\title{
Free Radical Ring-Opening Polymerization
}

\author{
William J. BAILEY \\ Department of Chemistry, University of Maryland, \\ College Park, MD 20742, U.S.A.
}

(Received August 20, 1984)

\begin{abstract}
Although unstrained five- or six-membered carbocyclic systems undergo free radical ring-closing polymerization, the introduction of an oxygen into the ring will promote free radical ring-opening polymerization, since the resulting carbon-oxygen double bond is approximately $50 \mathrm{kcal}$ more stable than a carbon-carbon double bond. Thus, cyclic ketene acetals, cyclic ketene aminals, cyclic vinyl ethers, unsaturated spiro ortho carbonates, and unsaturated spiro ortho esters will all undergo free radical ring-opening polymerization. Copolymerization of these monomers with a wide variety of vinyl monomers will introduce an ester, amide, keto or carbonate group into the backbone of an addition polymer and can make possible the synthesis of functionally terminated oligomers, biodegradable addition polymers, thermally stable polymers, and monomers that expand on polymerization.
\end{abstract}

KEY WORDS Free Radical Ring-Opening Polymerization / 2-Methylene-

1,3-dioxepane / Polyesters / Functionally-terminated Oligomers /

Unsaturated Spiro $o$-Carbonates /

Although the ionic ring-opening polymerization of heterocyclic compounds, such as ethylene oxide, tetrahydrofuran, ethyleneimine, $\beta$-propiolactone, and caprolactam, as well as the Ziegler-Natta ringopening of cyclic olefins, such as cyclopentene and norbornene, are well known, free radical ringopening polymerizations are rather rare. In fact, unstrained five- and six-membered carbocyclic rings are usually involved in ring-closing reactions rather than ring opening. For example, Butler and Angelo ${ }^{1}$ in 1957 reported that when diallyldimethylammonium bromide was polymerized by a free radical mechanism, a soluble polymer containing fivemembered rings was obtained by an inter-

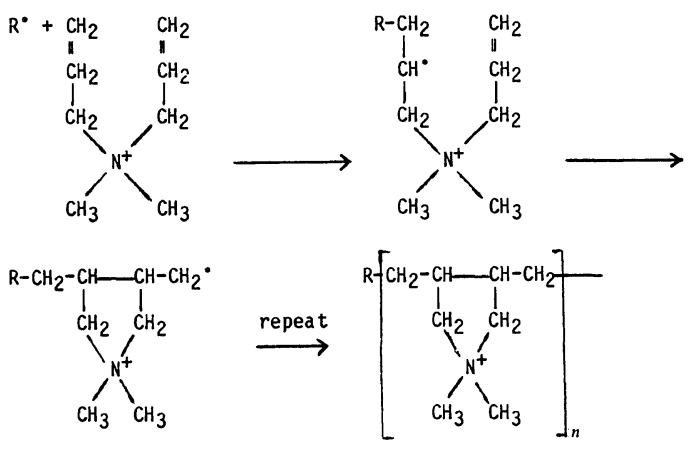

intramolecular polymerization. Apparently the reaction is kinetically controlled to form the fivemembered ring rather than the thermodynamically favored six-membered ring. The few examples of free radical ring-opening polymerization that are reported in the literature involve cyclopropane derivatives or highly strained bicyclic olefins. For example, Takahashi ${ }^{2}$ studied the free radical polymerization of vinylcyclopropane and reported that the cyclopropane ring opened to give a polymer containing about $80 \% 1,5$-units and about $20 \%$ of undetermined structural units. Apprarently the radical adds to the vinyl group to give the intermediate cyclopropylmethyl radical which opens at a rate faster than the addition to the double bond of another monomer. Somewhat similar results

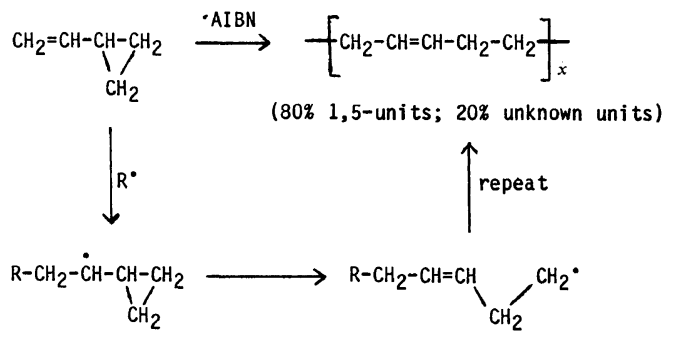




\section{W. J. BAILEY}

were obtained with the chloro derivatives. More recently, Cho and $\mathrm{Ahn}^{3}$ studied the related malonic ester derivative with similar results. Errede $\mathrm{e}^{4}$ found the dimer of $o$-xylylene would undergo free radical ring-opening polymerization to give the corresponding poly-o-xylylene. In this case the driving

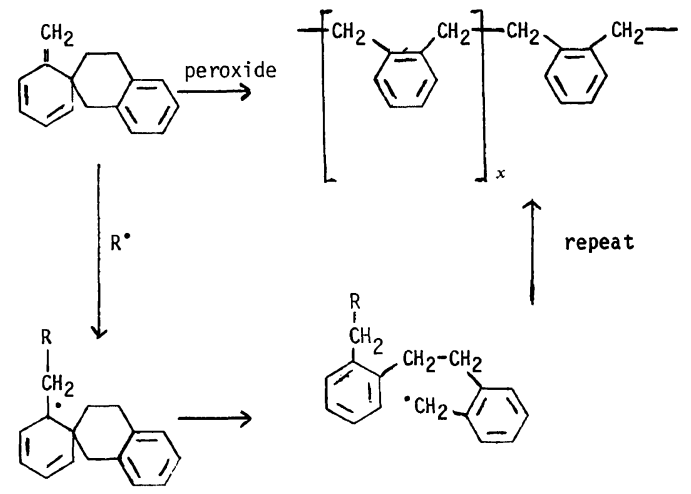

force for the ring-opening step is the formation of the aromatic ring. Hall and coworkers ${ }^{5}$ showed that derivatives of bicyclo[1.1.0]butane would polymerize by free radicals by cleavage of the highly strained central bond. Of course, the ring-open-

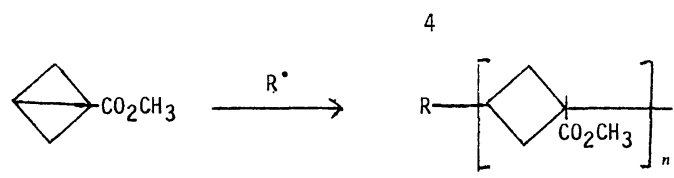

ing polymerization of $S_{8}$ has been postulated to involve free radicals. ${ }^{6}$

The course of some of these ring-opening and ring-closing polymerizations can be explained by the recent data of Maillard, Forest, and Ingold, ${ }^{7}$ who studied the transformations in the cyclopropylmethyl and the cyclopentylmethyl series by electron spin resonance. In the case of the three-membered radical the reaction involves ring-opening since the energy is favorable and the rate of the reaction is very high. In the case of the five-membered ring system the reaction proceeds in the direction of ring-closure since the energetics of that reaction is favorable and the rate of the ring closure is also moderately high. With the assumption that the carbon-oxygen double bond is at least $50-60 \mathrm{kcal}$ $\mathrm{mol}^{-1}$ more stable than the carbon-carbon double bond,$^{8}$ one can calculate that the introduction of an oxygen atom in place of the carbon atom in the cyclopentylmethyl radical would favor the reverse reaction or the ring opening. In other words the ring opening reaction would be favored by at least 40 $\mathrm{kcal} \mathrm{mol}{ }^{-1}$ by producing the more stable carbonyl double bond.

A search of the literature indeed revealed many ring systems containing an oxygen atom that would undergo a ring-opening reaction but not polymerization in the presence of free radical catalysts. One such case was the cyclic formal, ethylene formal. Maillard, Cazaux, and Lalande ${ }^{9}$ found that when ethylene formal was heated at $160^{\circ} \mathrm{C}$, it rearranged to ethyl formate. The reaction could be rationalized<smiles>[Z2]CCOC=O</smiles><smiles>C1COCOC1</smiles><smiles>CCOC=O</smiles><smiles>C1COCO1</smiles>

as indicated where the driving force for the ringopening reaction in the chain reaction was the

Table I.

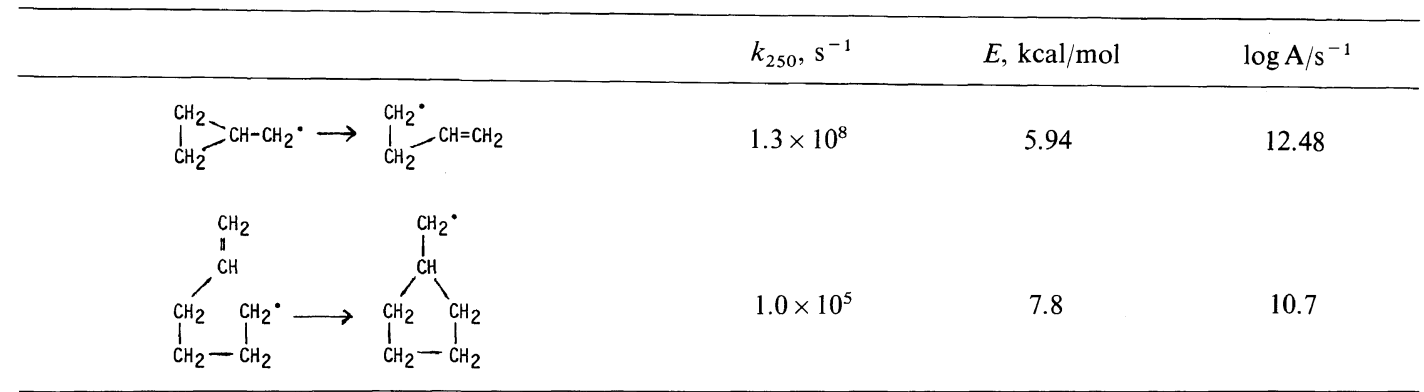


formation of the stable carbon-oxygen double bond in the final ester. With the knowledge that such a ring system would undergo cleavage, it seemed to be a fairly straight forward process to synthesize a monomer that would undergo ring-opening polymerization by introducting a double bond at the carbon atom flanked by the two oxygens.

The monomer desired for this ring-opening polymerization had indeed been prepared by McElvain and Curry ${ }^{10}$ in 1948. Although Johnson, Barnes, and McElvain ${ }^{11}$ had treated diethyl ketene acetal with peroxide and had reported that there was no reaction, no such study was reported for the 2methylene-1,3-dioxolane (I). A reinvestigation of the cyclic ketene acetal I was therefore undertaken. The ketene acetal I was found to be extremely sensitive to acid. ${ }^{12}$ Exposure of $\mathbf{I}$ to the atmosphere

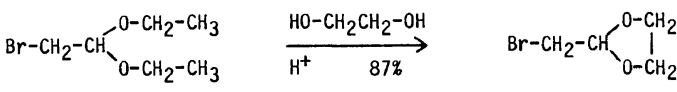

$$
\begin{aligned}
& \underset{62 \%}{\stackrel{t-\mathrm{BuOK}}{\longrightarrow}} \quad \mathrm{CH}_{2}=\mathrm{C}_{\mathrm{O}-\mathrm{CH}_{2}}^{-\mathrm{O}-\mathrm{CH}_{2}} \\
& \text { I }
\end{aligned}
$$

would cause immediate polymerization to give a polymer with little or no ring opening. In order to handle this monomer conveniently it was necessary to have some base, such as potassium tert-butoxide or a tertiary amine, always present; under these conditions no spontaneous polymerization would occur.

Treatment of this monomer I with benzoyl peroxide at high temperatures gave a high molecular weight polyester by a free radical ring-opening polymerization which can be rationalized by the accompanying scheme. This polyester is difficult to
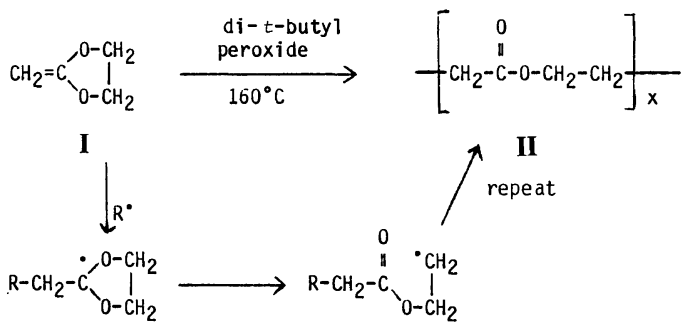

III

IV

synthesize with high molecular weight from the $\gamma$ hydroxybutyric acid or the very stable $\gamma$-butyrolactone, which is isomeric with $\mathbf{I}$.

At lower temperatures the ring-opening is not complete. Thus at $60^{\circ} \mathrm{C}$ only $50 \%$ of the rings are opened to give a random copolymer of the following structure ${ }^{12}$ :

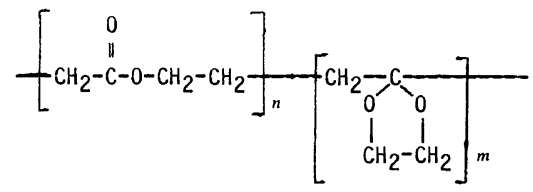

The structure of the polyesters was established by analysis as well as infrared and NMR spectroscopy. An alternative method of analysis of the extent of ring-opening was the basic hydrolysis of the copolymer II, which cleaved the ester groups but left the cyclic ketals intact.

Even at $120^{\circ} \mathrm{C}$ only $87 \%$ of the rings are opened. Apparently the unopened radical III can add directly to the monomer $\mathbf{I}$ in competition with the ring-opening process to form the open chain radical IV. High dilution was found to favor the ringopening process since the addition of III to the monomer $\mathbf{I}$ is a second order reaction while the conversion of III to the open chain radical is first order. The extent of ring opening is kinetically controlled with a direct competition between the rate of direct addition, $k_{11}$, and the rate of ring opening, $k_{\text {iso }}$.

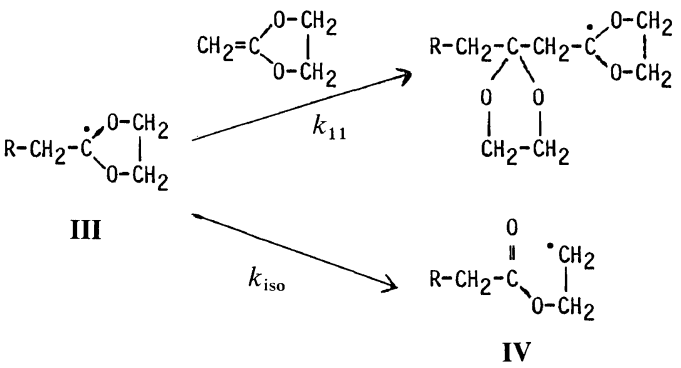

Any change in the system that would increase the steric hindrance of the cyclic radical would similarly increase the extent of ring opening by decreasing $k_{11}$. Similarly any change in the system that would produce a more stable radical upon ring opening would be expected to favor the ring opening process by increasing $k_{\text {iso }}$.

One of the intriguing characteristics of the ethylene ketene acetal is its ability to copolymerize with a wide variety of common monomers, including styrene and methyl methacrylate. One should note that this process introduces an ester group into the backbone of an addition polymer. Although the copolymerization of oxygen would introduce a per- 
oxide linkage into the backbone, this is the first time that a relatively stable but yet hydrolizable functional group has been introduced into the backbone of an addition polymer. ${ }^{13,14}$

In a program to find other cyclic ketene acetals that would undergo quantitative ring-opening even at room temperature we prepared the sevenmembered ketene acetal, 2-methylene-1,3-dioxepane $(\mathbf{V})$, which underwent essentially complete ring-opening at room temperature. ${ }^{15}$ Photoinitiated polymerization of $\mathbf{V}$ also gives complete ring opening. ${ }^{16}$ This process makes possible the quantitative introduction of an ester group in the backbone of an addition polymer.

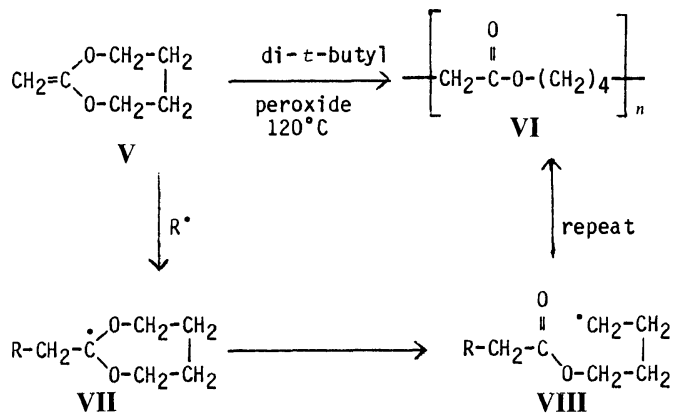

Apparently the seven-membered ring increases the steric hindrance in the intermediate free radical VII to eliminate practically all of the direct addition and also introduces a small amount of strain so that the ring-opening to the radical VIII is accelerated.

When the seven-membered ketene acetal $\mathbf{V}$ was copolymerized with styrene, a styrene copolymer containing ester groups in the backbone was obtained $\left(r_{1}=0.021\right.$ and $\left.r_{2}=22.6\right)$.

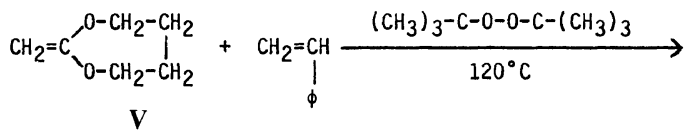

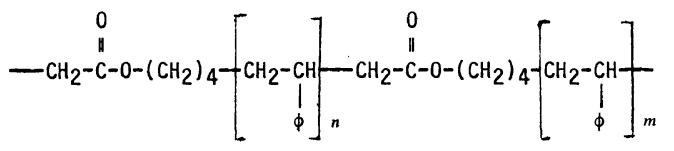

IX

Hydrolysis of these copolymers makes possible the synthesis of oligomers of styrene capped with a hydroxyl on one end and a carboxylic acid group on the other. ${ }^{17-19}$

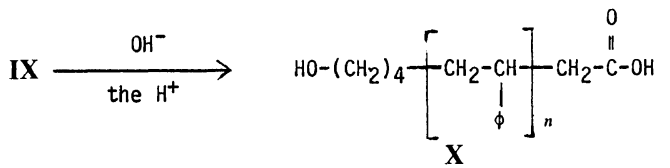

With a mixture containing about $80 \% \mathrm{~V}$ and $20 \%$ styrene, a copolymer containing $90 \mathrm{~mol} \%$ styrene and $10 \mathrm{~mol} \%$ ester-containing units was obtained. The hydrolysis of this copolymer gave an oligomer $\mathbf{X}$ of styrene containing an average of about nine styrene units end capped with the hydroxyl and carboxylic acid groups. Thus a very general method has been developed for the synthesis of a wide variety of oligomers with any desired molecular weight range. Of course, since the copolymers are random, the molecular weight distribution of the oligomers is quite broad. However, these oligomers should prove quite useful for the synthesis of polyurethanes and block polyesters.

Although most synthetic polymers are nonbiodegradable since they have not been on the earth long enough for microorganisms or enzyme systems to have evolved to utilize them as food, polyesters that are relatively low molecular weight and rather low melting are biodegradable. ${ }^{20}$ This observation is related to the fact that $\operatorname{poly}(\beta$-hydroxybutyric acid) occurs widely in nature and many microorganisms use this polyester to store energy in the same way that animals use fat. On the other hand, no synthetic addition polymer was known that was readily biodegradable. ${ }^{21}$ In an effort to produce a biodegradable addition polymer the 2-methylene1,3-dioxepane (V) and ethylene were copolymerized at $120^{\circ} \mathrm{C}$ for $30 \mathrm{~min}$ at a pressure of $1800 \mathrm{psi}$ to give a low conversion of copolymers XI with estercontaining units varying from 2.1 to $10.4 \mathrm{~mol} \%$. The copolymers were in fact biodegradable with the copolymers containing the high amount of ester groups being rapidly degraded and the copolymers containing only $2.1 \%$ comonomer only slowly degraded. Apparently there are enzymes in the microorganisms that are capable of hydrolyzing the ester linkages in the ethylene copolymer to produce the oligomers with terminal carboxylic acid groups; these oligomers are then degraded as analogs of fatty acids by the normal metabolic processes. ${ }^{22-24}$

Additional cyclic ketene acetals ${ }^{17-19}$ that have been studied have included the 4-phenyl-2-methylene-1,3-dioxolane (XIII) which undergoes quantitative ring-opening to give the polyester XIV. Ap- 
Free Radical Ring-Opening Polymerization

$$
\begin{aligned}
& \mathrm{CH}_{2}=\mathrm{CH}_{2}+\mathrm{CH}_{2}=\mathrm{C}^{\prime} \stackrel{\mathrm{O}-\mathrm{CH}_{2}-\mathrm{CH}_{2}}{-\mathrm{CH}_{2}-\mathrm{CH}_{2}} \underset{120^{\circ} \mathrm{C}}{\stackrel{\text { peroxide }}{\longrightarrow}} \\
& \text { V } \\
& -\mathrm{CH}_{2}-\mathrm{C}-0-\left(\mathrm{CH}_{2}\right)_{4}-\underset{\mathrm{XI}}{\mathrm{C}}\left[\mathrm{CH}_{2}-\mathrm{CH}_{2}\right]_{n}^{-} \stackrel{0}{\mathrm{CH}_{2}-\mathrm{C}-0-\left(\mathrm{CH}_{2}\right)_{4}-\left[\mathrm{CH}_{2}-\mathrm{CH}_{2}\right]_{m}} \\
& \underset{\text { then } \mathrm{H}^{+}}{\stackrel{\mathrm{OH}}{\longrightarrow}} \mathrm{HO}^{-}\left(\mathrm{CH}_{2}\right)_{4} \underset{-}{\left[-\mathrm{CH}_{2}-\mathrm{CH}_{2}\right]_{m}}-\mathrm{CH}_{2}-\mathrm{C}-\mathrm{OH}
\end{aligned}
$$

parently the ring-opening step from $\mathbf{X V}$ to $\mathbf{X V I}$ is greatly enhanced by the formation of the relatively stable benzyl radical in XVI even though $\mathbf{X V}$ is a five-membered ring analogous to the radical III.

Since the nitrogen analogs of the cyclic ketene acetals were readily synthesized and would polymerize with essentially $100 \%$ ring opening, their copolymerization with a variety of monomers was undertaken. ${ }^{28}$ Apparently the amide group is sufficiently more stable than the ester group that in contrast with the 2-methylene-1,3-dioxolane (I) the nitrogen analog XVII undergoes essentially quantitative ring opening. Copolymerization of XVII with styrene gives a copolymer XXI, which upon

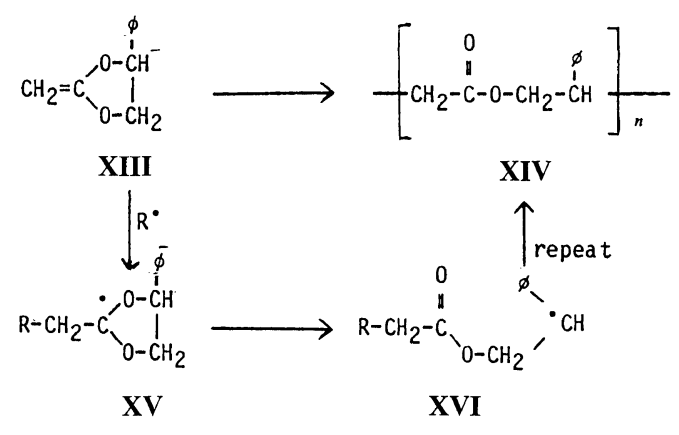

hydrolysis gives an oligomer capped with a methylamino group on one end and a carboxylic acid group on the other. ${ }^{19}$

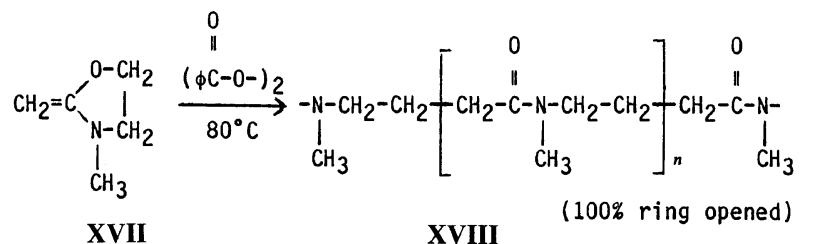

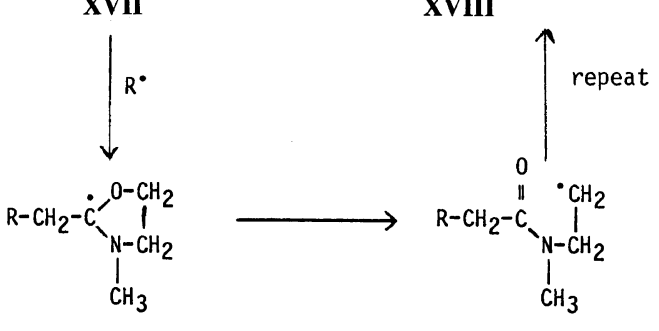

XIX

$\mathbf{X X}$

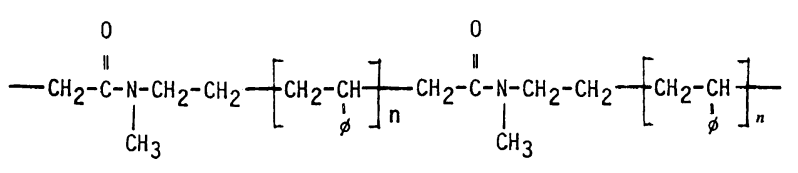

XXI 
Although the sulfur analog XXII of the cyclic ketene acetal I was prepared and polymerized, apparently the resulting thioester is higher energy than the ordinary ester and therefore retards the extent of ring opening. Even at $120^{\circ} \mathrm{C}$ only $45 \%$ of the rings were opened. ${ }^{29}$

$$
\mathrm{CH}_{2}=\mathrm{C} \underset{\substack{\mathrm{C}-\mathrm{CH}_{2} \\ \text { XXII }}}{\stackrel{\mathrm{S}-\mathrm{CH}_{2}}{\mid}}
$$

Since the nitrogen and sulfur analogs of the cyclic ketene acetal I gave interesting results, the study was extended to the carbon analog, the cyclic vinyl ethers. Thus, 2-methylenetetrafuran (XXIII) when treated with di-tert-butyl peroxide at $120^{\circ} \mathrm{C}$ gave a polymer XXIV, in which only about $5 \%$ of the rings had opened. ${ }^{28}$ Apparently the ketone group is

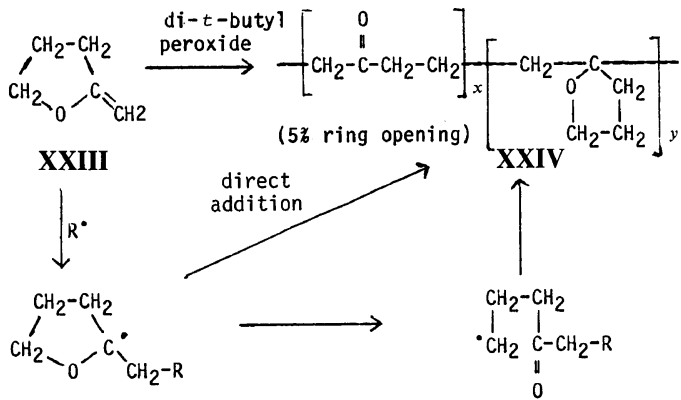

sufficiently less stable than the ester group that the extent of ring opening decreases from $87 \%$ for I to $5 \%$ for XXIII. Even when the cyclic vinyl ether XXIII was diluted with an equal volume of benzene, the ring opening increased only to $7 \%$.

Since the extent of ring-opening of the cyclic vinyl ethers is less than that of the cyclic ketene acetals, this series appeared to be an ideal system to study the effect of steric hindrance and the presence of radical-stabilizing substituents on the extent of ring opening. Thus the following monomers were prepared and polymerized at $120^{\circ} \mathrm{C}$ in the presence of di-tert-butyl peroxide. The number in parentheses

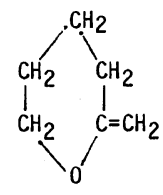

$(4-8 \%)$

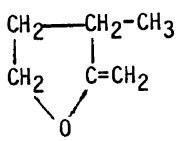

$(15-20 \%)$ indicate the extent of ring opening. The highest extent of ring opening in this series was observed for the 4-phenyl-2-methylenetetrahydrofuran (XXV).<smiles>C[C@H]1CCC[C@H]1O</smiles><smiles></smiles>

XXV

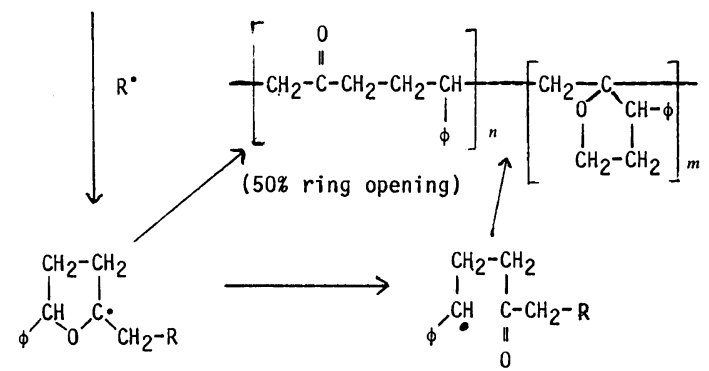

In this case the formation of the relatively stable benzyl radical helps promote ring cleavage so that about one half of the rings are opened. ${ }^{28}$

Even ring strain will not produce quantitative ring-opening in this series. Although the oxetane ring possesses considerable ring strain, the corresponding radical does not appear to open at a rapid rate. For example, 2-oxetanyl gives no signals in the ESR spectrum for the ring-opened product, which is in contrast to the five- and six-membered acetals which give the ring-opened radical signals at room temperature. ${ }^{30}$ For example, the polymerization of 2-methylenoxetane $(\mathbf{X X V I})^{31}$ at $120^{\circ} \mathrm{C}$ gave a copolymer in which only about $40 \%$ of the rings were opened. ${ }^{29}$ Apparently the small size of the ring reduces the steric hindrance so that the di-

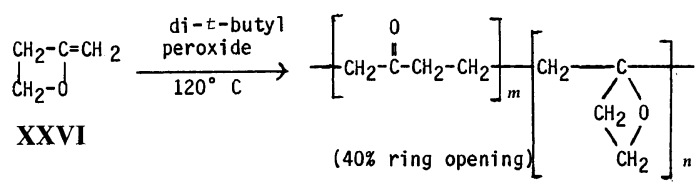

rect addition can effectively compete with the sluggish ring-opening step.

Ketene dimer (XXVII), which is an analog of the 2-methylenoxetane (XXVI), will undergo a higher extent of ring-opening on polymerization to give copolymers with different structures depending on whether the reaction is run in a sealed tube or open to the air. The extent of ring-opening is higher because the acyl radical XXIX is more stable than the primary radical that one would expect to obtain from the 2-methylenoxetane (XXVI). In the sealed tube the acyl radical XXIX does not lose very 


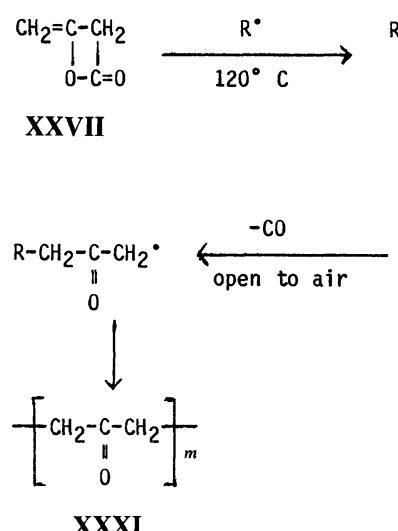

XXXI<smiles>[R]C[C@H](C)OC(=O)O</smiles>

XXVIII

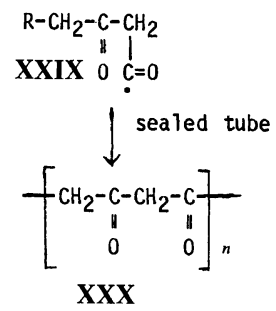

much carbon monoxide to give a copolymer $\mathbf{X X X}$ which contains a large amount of the 1,3-diketone structure. On the other hand the acyl radical XXIX, when the reaction is open to the air, can lose a substantial proportion of the acyl groups to give the copolymer XXXI which is largely the 1,4-diketone.

A surprising result was obtained from the polymerization of the 2-methylene-3,4-benzotetrahydrofuran (XXXII); XXXII gives a polymer XXXIII with little or no ring opening. Apparently the

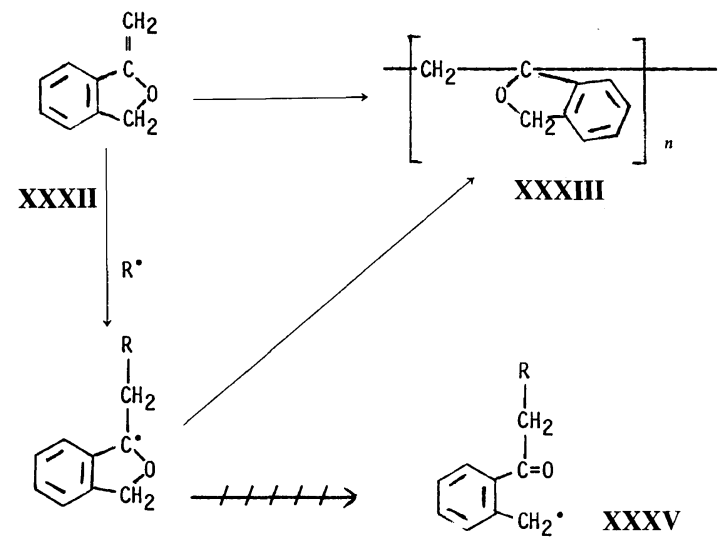

\section{XXXIV}

intermediate radical XXXIV, which is a tertiary benzyl radical with addition stabilization from the oxygen, is sufficiently more stable than the open chain primary benzyl radical XXXV that only direct addition takes place.

Copolymerization of several of these unsaturated cyclic ethers, particularly the 2-methylene-5-phenyltetrahydrofuran (XXV), with various mono-

mers is a convenient way to introduce a ketone group into the backbone of the addition polymer. Such copolymers containing the keto groups can be expected to be photodegradable. The competitive process involves the copolymerization of the monomer with carbon monoxide under high pressure. ${ }^{32}$

In a program to develop monomers that expand upon polymerization, we had prepared a series of spiro ortho esters, spiro ortho carbonates, trioxabicyclooctanes, and ketal lactones that could be polymerized with ring opening by ionic expansion in volume.$^{33}$ Since a large proportion of industrial polymers are prepared by free-radical polymerization, it was desirable to have available a series of monomers that would polymerize by a free radical process with no change in volume or slight expansion. Such monomers could be added to common monomers to produce copolymers with reduced shrinkage or expansion in volume. It was reasoned that the introduction of unsaturation into a spiro ortho carbonate would permit double ring opening with expansion in volume. For that reason we undertook the synthesis of 3,9-dimethylene1,5,7,11-tetraoxaspiro[5.5]undecane (XXXVI) by the following set of reactions. ${ }^{34}$

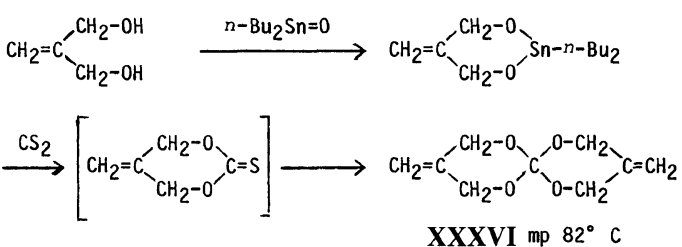

It was found when this monomer was treated with di-tert-butyl peroxide at $130^{\circ} \mathrm{C}$ and the reaction stopped below $30 \%$ conversion, a soluble polymer was obtained having a structure of a polycarbonate with pendant methylene groups. The structure of the polymer was established by elemental analysis as well as infrared and NMR spectroscopy. A very similar polymer could be attained by treatment of the monomer with boron trifluoride etherate at low conversions. The mechanism of the polymerization appeared to involve a radical double ring-opening according to the following mechanism:

The driving force for the double ring-opening polymerization apparently is the relief of the strain at the central spiro atom as well as the formation of the stable carbonyl group. ${ }^{35}$ 
$\mathrm{RO}+$

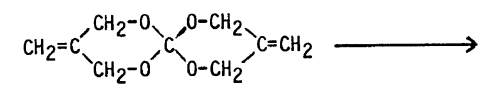

XXXVI

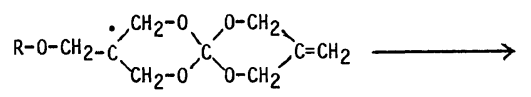

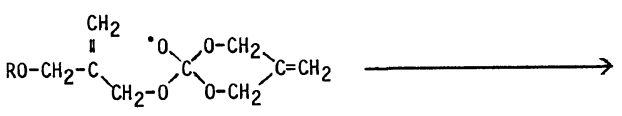

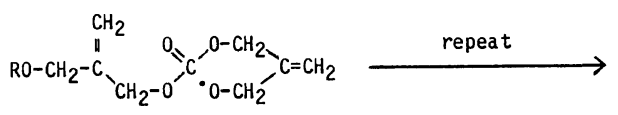

${ }_{\mathrm{RO}}-\left[\begin{array}{ccc}\mathrm{CH}_{2} & 0 & \stackrel{\mathrm{CH}_{2}}{\|} \\ \mathrm{CH}_{2}-\mathrm{C}-\mathrm{CH}_{2}-\mathrm{O}-\mathrm{C}-\mathrm{O}-\mathrm{CH}_{2}-\mathrm{C}-\mathrm{CH}_{2}-\mathrm{O}\end{array}\right]_{x}$

At high conversion this monomer produced a highly crosslinked resin very similar in appearance to the material produced from the polymerization of diallyl carbonate. The volume change that occurred during homopolymerization was quite unusual. At room temperature, a $4.3 \%$ expansion in volume occurred, while just below its melting point at $70^{\circ} \mathrm{C}$, a $7 \%$ expansion in volume occurred; at $85^{\circ} \mathrm{C}$ a $2 \%$ expansion took place; and the expansion decreased until above $115^{\circ} \mathrm{C}$ a slight shrinkage occurred. It is obvious from these data that the large expansion in volume that occurs below the melting point involves not only the increase in volume due to the double ring opening, but also a change in volume of $3-6 \%$ due to the process of going from a crystalline monomer to a liquid monomer. Since the monomer is a crystalline solid, it is difficult to find examples of homopolymerization in which the full $7 \%$ expansion in volume can be utilized. However, in copolymerizations it is possible to use a slurry of the crystalline monomer in a liquid monomer so that as copolymerization progresses, the crystalline monomer dissolves with some expansion and also polymerizes with expansion. ${ }^{36-41}$

The dimethylene spiro ortho carbonate XXXVI was shown to copolymerize with a variety of monomers, including methyl methacrylate, hydroxyethyl methacrylate, styrene, and diallyl carbonate. With methyl methacrylate XXXVI was shown to be less reactive with reactivity ratios of $r_{1}=0.87$ and $r_{2}=16.4$. Since $r_{1} \cdot r_{2}$ is greater than 1 , this fact

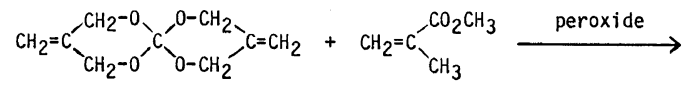

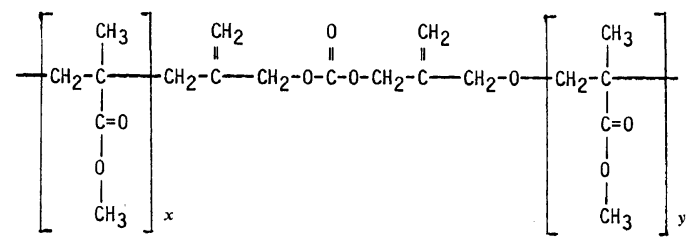

was interpreted as involving association of XXXVI in the monomer mixture rather than existing in a homogeneous solution. In this copolymerization if the monomer mixture contains $10 \%$ XXXVI and $90 \%$ methyl methacrylate and the reaction is stopped at $69 \%$ conversion, the copolymer contained only $1 \%$ of the carbonate units.

Since the carbonate group is a relatively easy group to hydrolyze, several other uses of these copolymers were suggested. A copolymer of the

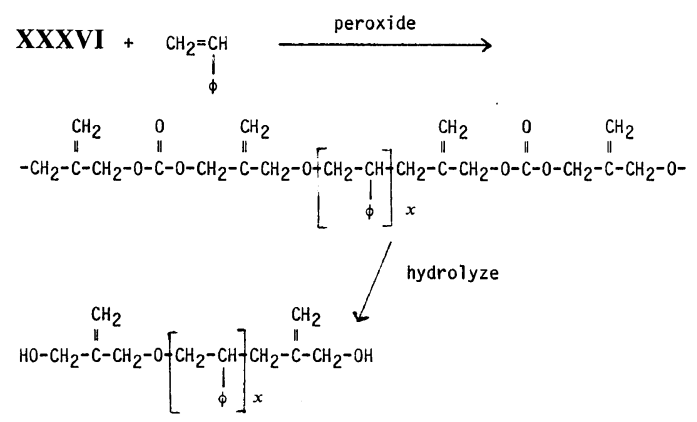

dimethylene monomer XXXVI and styrene was hydrolyzed to produce a hydroxy-terminated polystyrene. The use of other monomers that polymerize by ring-opening should permit the synthesis of a variety of addition polymers containing a wide assortment of functional endgroups.

A potential use of this monomer is in the area of dental fillings in which a slurry containing $20 \%$ of very fine crystals of the unsaturated spiro ortho carbonate XXXVI and $60 \%$ of the adduct of methacrylic acid to bisphenol- $A$ diglycidyl ether (Bis-GMA) plus $20 \%$ trimethylolpropane trimethacrylate produces a material with essentially no change in volume upon polymerization. An investigation of a bubble test on tooth enamel showed that this copolymer had nearly double the adhesion to the tooth structure that the base resin had without the addition of the unsaturated spiro 
ortho carbonate. ${ }^{42}$ The copolymer also had improved impact strength but yet essentially the same modulus, and filled composites appeared to have somewhat improved abrasion resistance.

Since a variety of unsaturated hererocyclic monomers will undergo ring-opening polymerization quite readily, it appeared desirable to prepare a related spiro ortho ester for use as a monomer with either no change in volume or slight expansion. Thus an unsaturated spiro ortho ester was synthesized by the accompanying reaction. Polymerization of the 2-methylene-1,4,6-trioxaspiro[4.4]nonane with benzoyl peroxide gave a polymer with<smiles>OC[C@H](O)CBr</smiles><smiles>O=C1CCCO1</smiles>

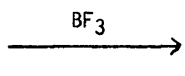<smiles>CC1COC2(CCCO2)O1</smiles>

XXXVII a complex structure that indicated that at $120^{\circ} \mathrm{C}$, only about $10 \%$ ring-opening had occurred. Apparently the radical adds to the double bond to give the intermediate XXXVIII which can add to another monomer or undergo ring-opening to give the semiopened radical XXXIX. XXXIX in

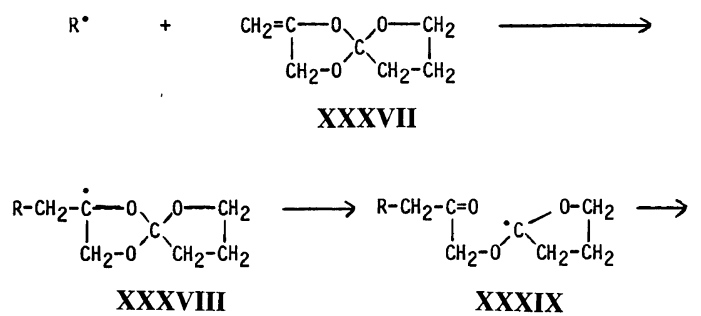<smiles>[R]CC(=O)OCCCCC</smiles>

$\mathbf{X L}$

turn can either add to a monomer or undergo a second ring-opening to give the double ring-opened radical XL. In fact the final polymer XLI has about $90 \%$ unopened units and about equal quan-

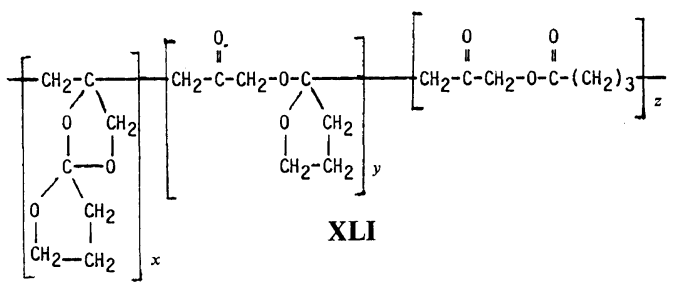

tities of the semiopened and double opened units. $^{43-45}$

However, when the strained unsaturated spiro ortho ester XLII was polymerized, essentially complete double ring opening occurred. Apparent-
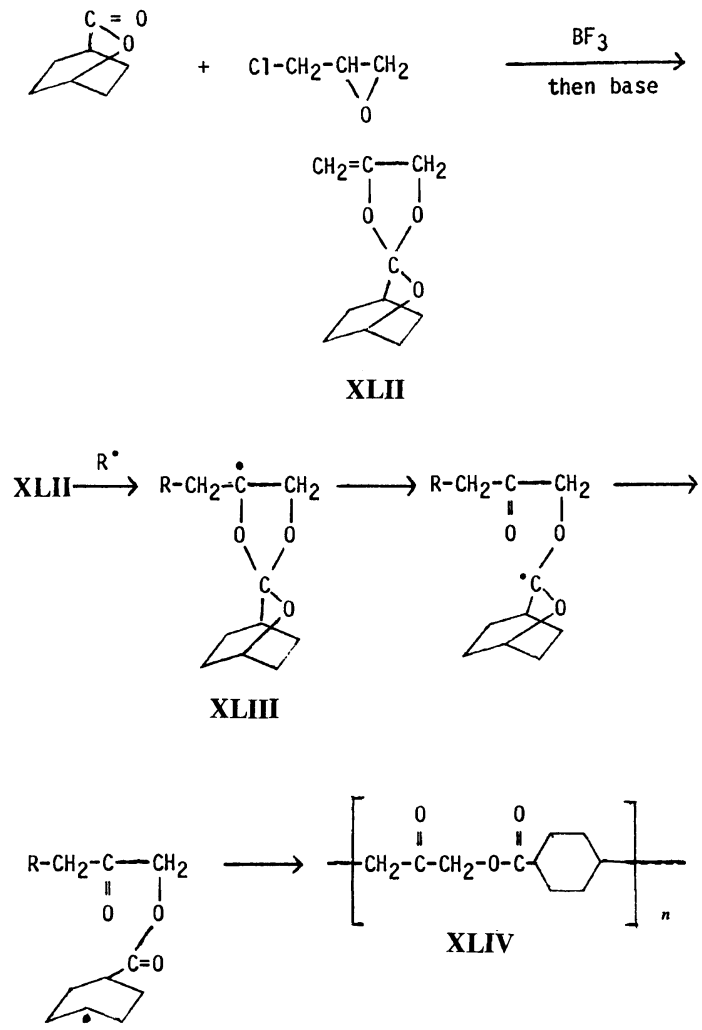

ly the intermediate radical XLIII has sufficient strain to promote the ring opening. The resulting polymer XLIV is intriguing since it contains both ester groups and keto groups. Such a polymer should be both biodegradable and photodegradable.

Thus we have been able to demonstrate that free radical ring-opening of unsaturated heterocyclic monomers is a very general phenomenon. This 
reaction has been shown to be for the first time a way to introduce functional groups, such as ester, amides, thioester, carbonates, and ketones, into the backbone of an addition polymer. As a consequence this copolymerization is a useful method for the synthesis of oligomers that can be capped on both ends with reactive groups, such as carboxyl, amino, mercapto, and hydroxyl, for the synthesis of biodegradable and photodegradable polymers, and for the stabilization of copolymers against decomposition by reverse polymerization. Free radical double ring opening polymerization is useful to control the shrinkage of monomers during free radical polymerization.

This work was supported in part by the Polymer Program of the National Science Foundation, the Frasch Foundation, and the Goodyear Tire and Rubber Company.

\section{REFERENCES}

1. G. B. Butler and R. J. Angelo, J. Am. Chem. Soc., 79, 3128 (1957).

2. T. Takahashi, J. Polym. Sci., A, 6, 403 (1968).

3. I. Cho and K. D. Ahn, J. Polym. Sci., Polym. Lett. Ed., 15, 751 (1977).

4. L. A. Errede, J. Polym. Sci., 49, 253 (1961).

5. H. J. Hall, Jr., and P. Ykman, Macromol. Rev., 11, 1 (1976).

6. A. V. Tobolsky and A. Eisenberg, J. Am. Chem. Soc., 81, 780 (1959).

7. B. Maillard, D. Forrest, and K. U. Ingold, J. Am. Chem. Soc., 98, 7024 (1976).

8. A. Streitwieser, Jr., and C. H. Heathcock, "Introduction to Organic Chemistry," 2nd ed, Macmillan Publishing Company, New York, 1981, p 1195.

9. B. Maillard, M. Cazaux, and R. Lalande, Bull. Soc. Chim. Fr., 1368 (1973).

10. S. M. McElvain and M. J. Curry, J. Am. Chem. Soc., 70, 3781 (1948).

11. P. R. Johnson, H. M. Barnes, and S. M. McElvain, J. Am. Chem. Soc., 62, 964 (1940).

12. W. J. Bailey and N. Yamazaki, in press.

13. W. J. Bailey, Polym. Prepr., Am. Chem. Soc., Div. Polym. Chem., 27(1), 210 (1984).

14. W. J. Bailey, P. Y. Chen, S.-C. Chen, W.-B. Chiao, T. Endo, B. Gapud, Y.-N. Lin, Z. Ni, C.-Y. Pan, S. E. Shaffer, L. Sidney, S.-R. Wu, N. Yamamoto, N. Yamazaki, and K. Yonezawa, "Free Radical RingOpening Polymerization" in "Symposium Honoring Prof. Carl S. Marvel," H. Marks and E. Pearce, Ed., Marcel Dekker, New York, 1984.

15. W. J. Bailey, Z. Ni, and S.-R. Wu, J. Polym. Sci.,
Polym. Chem. Ed., 20, 2420 (1982).

16. T. Endo, M. Okawara, W. J. Bailey, K. Azuma, K Nate, and H. Yokono, J. Polym. Chem., Polym. Lett. Ed., 21, 373 (1983).

17. W. J. Bailey, P. Y. Chen, W.-B. Chiao, T. Endo, L. Sidney, N. Yamamoto, N. Yamazaki, and K. Yonezawa, "Contemporary Topics in Polymer Science," Vol. 3, M. Shen, Ed., Plenum Publishing Corporation, New York, 1979, p 29.

18. W. J. Bailey, B. Gapud, Y.-N. Lin, Z. Ni, and S.-R. Wu, Polym. Prepr., Am. Chem. Soc., Div. Polym. Chem., 27(1), 142 (1984).

19. W. J. Bailey, T. Endo, B. Gapud, Y.-N. Lin, Z. Ni, C.-Y. Pan, S. E. Shaffer, S.-R. Wu, N. Yamazaki, and K. Yonezawa, Preprints, Japan-U.S. Seminar on Synthesis and Reactions of Oligomers and EndReactive Polymers, Osaka, Japan, Oct. 17-20, 1983, p 74.

20. J. E. Potts, R. A. Clendinning, W. B. Ackart, and W. D. Niegisch, "Polymers and Ecological Problems," J. Guillet, Ed., Plenum Press, New York, 1973, p 61

21. W. J. Bailey, "Proceedings of the Third International Conference on Advances in the Stabilization and Controlled Degradation of Polymers," Lucerne, Switzerland, June 1, 1981, p 12.

22. W. J. Bailey and B. Gapud, Polym. Prepr., Am. Chem. Soc., Div. Polym. Chem., 27(1), 58 (1984).

23. W. J. Bailey, "Proceedings of the Sixth International Conference on Advances in the Stabilization and Controlled Degradation of Polymers," Lucerne, Switzerland, May 22-24, 1984, p 38.

24. W. J. Bailey and B. Gapud, Annals of the New York Academy of Sciences, in press.

25. W. J. Bailey, S.-R. Wu, and Z. Ni, J. Macromol. Sci.Chem., A18(6), 973 (1982).

26. W. J. Bailey, Z. Ni, and S.-R. Wu, Macromolecules, 15, 711 (1982)

27. W. J. Bailey, S.-R. Wu, and Z. Ni, Makromol. Chem., 183, 1913 (1982).

28. W. J. Bailey, A. Arfaei, P. Y. Chen, S.-C. Chen, T. Endo, C.-Y. Pan, Z. Ni, S. Shaffer, L. Sidney, S.-R. $\mathrm{Wu}$, and N. Yamazaki, "Proceedings IUPAC 28th Macromolecular Symposium," Amherst, Mass., July 12-16, 1982, p 214.

29. L. Sidney, S. E. Shaffer, and W. J. Bailey, Polym. Prepr., Am. Chem. Soc., Div. Polym. Chem., 22(2), 373 (1981)

30. A. J. Dobbs, B. C. Gilbert, and R. O. C. Norman, J. Chem. Soc., A, 124 (1971); J. Chem. Soc., Perkin Trans., 2, 786 (1972).

31. P. Hudrlik, A. Hudrlik, and C. Wan, J. Org. Chem., 40, 1116 (1975).

32. P. Columbo, M. Steinberg, and J. Fontana, J. Polym. Sci., B, 1, 447 (1973).

33. W. J. Bailey, R. L. Sun, H. Katsuki, T. Endo, H. Iwama, R. Tsushima, K. Saigo, and M. M. Bitritto, 
“ACS Symposium, No. 59, Ring-Opening Polymerization," T. Saegusa and E. Goethals, Ed., American Chemical Society, Washington, D. C., 1977, p 38.

34. W. J. Bailey, H. Katsuki, and T. Endo, Polym. Prepr., Am. Chem. Soc., Div. Polym. Chem., 15, 445 (1974).

35. T. Endo and W. J. Bailey, J. Polym. Sci., Polym. Lett. Ed., 13, 193 (1975).

36. T. Endo and W. J. Bailey, J. Polym. Sci., Polym. Chem. Ed., 13, 2525 (1975).

37. W. J. Bailey, Kobunshi, 30, 331 (1981).

38. W. J. Bailey and T. Endo, J. Polym. Sci., Polym. Symp., 64, 17 (1978).

39. T. Endo and W. J. Bailey, Makromol. Chem., 176,
2897 (1975).

40. W. J. Bailey and T. Endo, J. Polym. Sci., Polym. Chem. Ed., 14, 1735 (1976).

41. T. Endo, M. Cai-Song, M. Okawara, and W. J. Bailey, Polym. J., 14, 485 (1982).

42. V. P. Thompson, E. F. Williams, and W. J. Bailey, $J$. Dental Res., 58, 522 (1979).

43. T. Endo and W. J. Bailey, J. Polym. Sci., Polym. Lett. Ed., 18, 25 (1980).

44. T. Endo, M. Okawara, N. Yamazaki, and W. J. Bailey, J. Polym. Sci., Polym. Chem. Ed., 19, 1283 (1981).

45. H. Fukuda; M. Hirota, T. Endo, M. Okawara, and W. J. Bailey, J. Polym. Sci., Polym. Chem. Ed., 20, 2935 (1982). 